\title{
Device Design for Electric Arc Electromagnetic Constriction
}

\author{
Miguel Guilherme Antonello ${ }^{1,2}$ (D) , Alexandre Queiroz Bracarense ${ }^{2}$ (D) \\ ${ }^{1}$ Colégio Técnico Industrial de Santa Maria, Universidade Federal de Santa Maria, Santa Maria, Rio Grande do Sul, Brasil. \\ ${ }^{2}$ Departamento de Engenharia Mecânica, Universidade Federal de Minas Gerais, Belo Horizonte, Minas Gerais, Brasil.
}

Como citar: Antonello MG, Bracarense AQ. Device design for electric arc electromagnetic constriction. Soldagem \& Inspeção. 2019;25:e2539. https://doi.org/10.1590/0104-9224/SI25.39

\begin{abstract}
The difference of potential between two electrodes results in electric current breaking the dielectric barrier of the gas in this space causing a plasma discharge called electric arc. As a result, there is luminosity and an increase in temperature. Electric arc is used for welding and usually one of the electrodes is cylindrical with small diameter and the other with large area. Because of this configuration, the side section of the electric arc has a bell shape and forms a circular impression in contact with the work piece (the weld pool). With the use of electromagnetic forces, it is possible to change this circular impression, completely changing the behavior and consequently the geometry of the weld pool. This article presents the development and construction of a device for the electromagnetic constriction of the electric arc, capable of changing the cross section of the impression from circular to elliptical. The steps performed in the article were the simulation of the electromagnetic fields generated to change the electric arc shape, the development of the arc constriction device and the application of this electromagnetic constriction in beads on plate. The results show that the electromagnetic forces change the transverse profile of the arc from circular to elliptical, enabling the increase in specific power and a more precise orientation of the electric arc. Also, changing the orientation of the ellipse results in different penetration and width of the bead.
\end{abstract}

Key-words: Electric arc constriction; Electromagnetism; Arc welding; GTAW.

\section{Projeto de um dispositivo para constrição eletromagnética do arco elétrico}

Resumo: A diferença de potencial entre dois eletrodos resulta em corrente elétrica ao romper a barreira dielétrica do gás neste espaço e ocasionar uma descarga de plasma chamada de arco elétrico. Como resultado se tem luminosidade e aumento de temperatura. Usualmente em soldagem a arco, um eletrodo é cilíndrico de menor diâmetro e o seu oposto é a área de soldagem de maior dimensão. Com isso, a seção lateral deste arco elétrico tem um perfil de sino e forma uma impressão circular no contato com a peça. Com o uso de forças eletromagnéticas é possível alterar essa impressão circular, alterando completamente o comportamento e consequentemente a geometria da poça de soldagem. Este artigo apresenta o desenvolvimento e a construção de um dispositivo para constrição eletromagnética do arco elétrico, capaz de alterar a seção transversal da impressão de circular para elíptica. As etapas realizadas foram a de simulação dos campos eletromagnéticos gerados para alterar a forma do arco elétrico, o desenvolvimento do dispositivo para constrição do arco e a aplicação desta constrição eletromagnética em cordões sobre chapa. Os resultados mostram que as forças eletromagnéticas alteram o perfil transversal do arco de circular para elíptico, possibilitando o aumento da potência específica e uma orientação mais precisa deste arco elétrico. Adicionalmente, ao modificar a orientação da elipse, resulta em diferente penetração e largura do cordão.

Palavras-chave: Constrição do arco elétrico; Eletromagnetismo; Soldagem a arco; GTAW.

\section{Introduction}

The electric arc welding process, intrinsically, generates an electromagnetic field from the welding current flow through the electrode, the electric arc, the fusion pool and the component to be welded. This magnetic field has transversal components that determine the position of the arc in the liquid metal, and longitudinal components that favor the rotation of the arc combined with the movement of the liquid metal [1].

The shape of the electric arc can be affected by electromagnetic forces; the electromagnetic field generated by solenoids causes the electric arc to deflect and influences on increased penetration, when compared to not using the electromagnetic field [2].

Recebido: 12 Aug., 2020, Aceito 21 Oct., 2020

E-mails: antonello@ctism.ufsm.br (MGA), queiroz@demec.ufmg.br (AQB)

This is an Open Access article distributed under the terms of the Creative Commons Attribution Non-Commercial License which permits unrestricted noncommercial use, distribution, and reproduction in any medium provided the original work is properly cited. 
An external magnetic field causes effects on the electric arc when applied on it, enabling to modify the shape of the electric arc, to interfere in the arc stability, to control the transfer of the drops, to influence the solidification of the weld pool, to optimize the appearance of the weld bead, but also to improve the microstructural characteristics and mechanical properties of the weld $[3,4]$.

In addition to the influence on the electric arc, electromagnetic forces can be used to control the flow of molten metal from the melt pool. In fusion welding, gravity causes the liquid metal in the weld pool to follow the direction of gravity, which can cause irregularities and defects in the weld bead. With the use of an electromagnetic control in the weld pool, it was possible to even the appearance of the bead, both in flat and overhead positions, combining the intensity of the electromagnetic field and the inclination of the GTAW torch [5].

The welding current and shielding gas have an influence on the metal transfer mode in the GMAW process. Other important factors are the external electromagnetic forces that affect the metal transfer, the short circuit rate, the spatter generation rate and the properties of the weld metal, in addition to being able to insert, with the application of a longitudinal electromagnetic field, a rotational transfer mode in the electric arc [6]. Another positive effect, when using the external magnetic field for high speed welding in the GTAW process, is the improvement in the quality of the weld bead with the attenuation of the humping effect [7].

The patent for a magnetic arc oscillator during welding with the GMAW process, in the early 1960s, drew attention to the application of magnetism in welding [8]. Later, after the research by Brown et al. in the year 1962, several researchers began to study the effects of the magnetic field initially on the crystallization of the weld pool. The studies were concentrated on the type of magnetic field and on the phenomena caused in welding such as the arc shape and metallic transfer [9].

The use of different patterns and frequency of magnetic arc oscillation, using the powered GTAW process, proved to be efficient in the construction of thin walls, minimizing the overflow of the weld pool and increasing the efficiency of deposition. The effect of the electric arc movement acts on the liquid metal by distributing the heat over a larger area, decreasing the power density, reducing the temperature and the volume of the weld pool [10].

In addition to magnetic oscillation, the use of magnetism to change the shape of the electric arc has been the object of study in arc welding. In the experiment conducted by Yunlong et. al. [11], the images obtained from the camera, it was observed that under the action of the longitudinal magnetic field the upper end of the arc contracts and the lower end expands. The bell shape would rotate at high speed according to the parameters of current and frequency that the coil generating the electromagnetic field feeds.

With a helical electromagnetic coil, concentric to the welding torch in the CMT (cold metal transfer) process, the magnetic effect on the arc behavior was observed. As the current on the coil increased, the width of the arc base increased and the height decreased. This modification of the electric arc profile affects the thermal input on the base metal and the behavior of the melting pool, with an increase in the heating area, the thermal input decreases and also provides a spreading of the melting pool [12]. In the same configuration of the concentric coil, the effect of the magnetic oscillation provided changes in the geometry of the bead deposited by the CMT process. The deposited beads showed a reduction in penetration and reinforcement, with an increase in width. The effect of this concentric oscillation to the electric arc increased the contact area of the arc with the part, thereby reducing the thermal input per unit area, causing the weld pool to move in the direction of spreading the metal deposited on the substrate [13].

Still using the CMT process, the application of an external axial magnetic field with variation of intensity and frequency of the magnetic induction, both the arc and the molten drops were rotated by the Lorentz force. This forced rotational movement, in addition to homogenizing the heat distribution in the base metal, alters the microstructure and mechanical properties of the union of dissimilar aluminum alloys with stainless steel, with a $45 \%$ increase in the joint tensile strength when compared to a situation of not using the external magnetic field [14].

The magnetic effects on the electric arc were also investigated using permanent magnets. The use of four permanent magnets around the electric arc enables the external magnetic field to change the shape of the electric arc from conical to a flattened cone. Also, the circular section of the arc has been transformed into an elliptical section. The use of high-performance permanent magnets, arranged around the GTAW torch, improved the appearance of the bead at high speeds of welding, in addition to changing the bead width and modifying the depth/width ratio $[9,15-17]$. The parameters that can be regulated for the magnetic field generated by the permanent magnets are the angle and direction of this field. The magnetic field perpendicular to the arc column has better constriction effect than the magnetic field parallel to this arc column. Constriction reduces the melted area with increased penetration [18]

When changing the electric arc shape, its contact area with the part is changed. A heat source transfers the energy to the part through a contact area $\left(A_{0}\right)$. In order to provide localized fusion of the base metal, the source must supply energy at a high rate and in a smaller area. The specific power $\left(P_{\text {esp }}\right)$ quantifies this requirement according to Equation 1. The amount of energy generated by the heat source is given by $E, \eta$ is the thermal efficiency of the source and the time is represented by $t$ [19]. 


$$
P_{e s p}=\frac{\eta E}{t \cdot A_{0}}
$$

The thermal efficiency $(\eta)$ of a welding process indicates how much of the energy from the source is effectively transferred to the part. This performance is a dimensionless factor dependent on the process and it varies with some operational parameters, in the GTAW process it varies with the welding current, polarity, electrode sharpening angle, shielding gas flow, arc length, feed wire and helium content [20].

An electric charge has the ability to modify its surroundings due to the generation of an electric field around it. This electric field is a vector field capable of acting on other charges that are immersed in this field [21].

The electromagnetic force, or Lorentz force $(F)$, is capable of moving electrical charges $(q)$ due to the composition of electrostatic components $(E)$ and magnetic components $(B)$. The magnetic force is only responsible for changing the direction of movement, without changing the kinetic energy [22]. In the physics of welding, the electromagnetic component is usually much larger than the electrostatic component, and for that reason the term for the electrostatic component can often be deleted [23]. Lorentz force is calculated according to Equation 2 that follows:

$\vec{F}=q(\vec{E}+\vec{v} x \vec{B})$

A straight wire generates a magnetic field concentric to the conductor when a current run through it. According to the Biot-Savart Law for a rectilinear conductor, Equation 3 shows that the field depends on the magnetic permeability of the medium, the current and the distance from the center of this conductor $[22,24]$.

$B=\frac{\mu_{0} I}{2 \pi r}$

A solenoid is formed when winding the conductor in helical form. The superposition of the conductor's electromagnetic fields creates a more intense field maintaining the structure of the generated field. In this configuration, the number of turns is capable of intensifying the magnetic field, the paths of the field vectors become very straight inside and outside right next to the coil. On the other hand, close to the edges of the coil and externally away from the turns, the field is not constant and becomes more difficult to calculate [24]. Equation 4 is applied to solenoids with a number of turns equal to $N, \mu_{0}$ is the magnetic permeability of the medium and $L$ is the side length of the coil.

$B=\frac{\mu_{0} I N}{L}$

In this article the project of a device for electromagnetic constriction of the electric arc in the GTAW process and its application in bead on plate welding is detailed. The design stage consisted of the electromagnetic simulation of the field generated by the geometry of the set, followed by three-dimensional modeling, the fabrication of the constricting device and the application over the electric arc to accomplish the constriction. Also, it was verified if the constricting device provides the alteration of the electric arc profile and the geometric characteristics of the beads.

\section{Materials and method}

\subsection{Device design}

In order to constrict the electric arc, the geometry of the device arranged the electromagnetic field so that the resulting force compressed the arc electric charges, immersed in this field. The electromagnetic simulation of the coils with the tungsten electrode and ceramic nozzle set was configured in the FEMM (Finite Element Method Magnetics) software. The electromagnetic field generated around the electric arc is transversal to the direction of the welding current. This software allows building a twodimensional simulation considering the different materials involved; Figure 1 shows a top view of the simulation configuration. Figure $1 \mathrm{a}$ shows the materials and the mesh generation, while Figure $1 \mathrm{~b}$ shows the electromagnetic field resulting from the interaction of the coils with the welding current. 


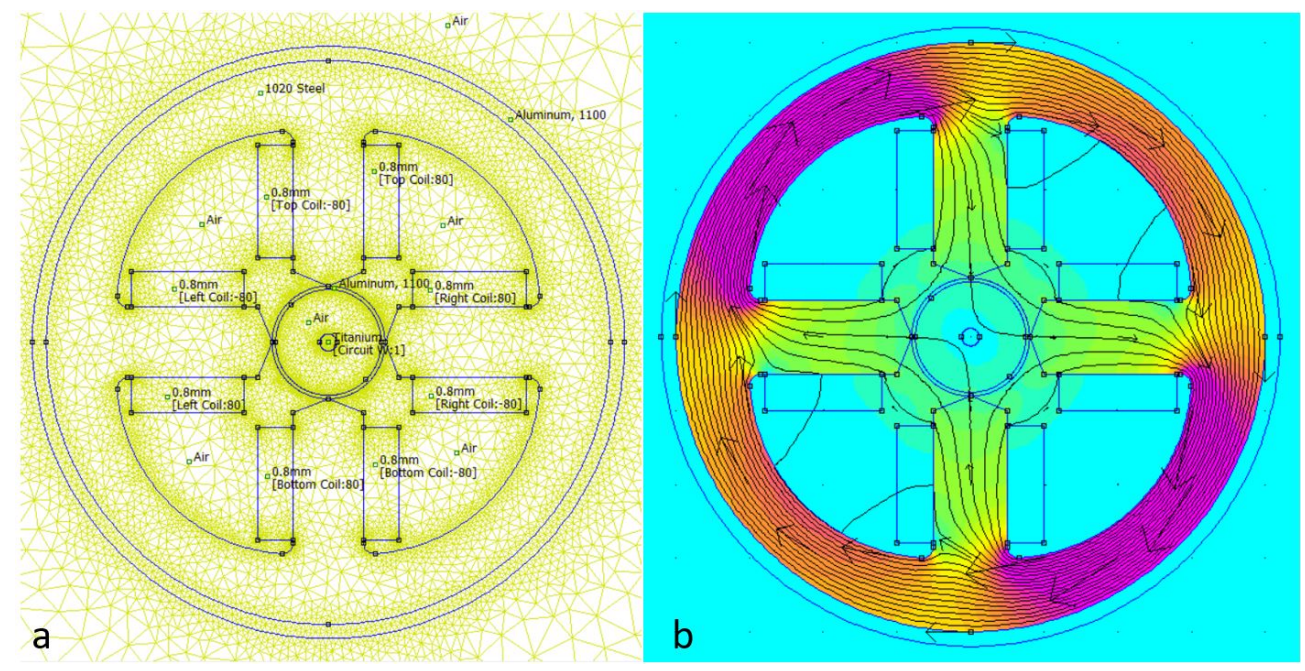

Figure 1. Electromagnetic simulation of the constricting device.

This configuration features four helical coils equidistant to the center of the electric arc region, wound over a SAE 1020 carbon steel cylindrical air gap. Each coil has 80 loops of $0.8 \mathrm{~mm}$ diameter copper wire. The tungsten electrode and the ceramic nozzle No. 8 are positioned in the center. The side coils, considering any of them as a reference, are electrically powered in the opposite direction of the immediate neighbor; this makes the field lines form a harmonious and closed path. Due to the geometry at the tip of the rods, the electromagnetic field lines are divided from one rod to another involving the region of the electric arc, thus the electric arc loads are immersed in this electromagnetic field perpendicular to the direction of the welding current.

It is possible to consider the tungsten electrode and electric arc assembly to be a straight wire, composed of a solid conductor (tungsten) and a conductor in plasma shape (electric arc). A top view representing the 2.4 mm tungsten electrode with a 120 A welding current, shown in Figure 2, shows that the electromagnetic field generated changes direction when reversing polarity. In direct current electrode negative (DCEN) polarity the field is clockwise and in direct current electrode positive (DCEP) polarity the electromagnetic field is counterclockwise (right hand rule).

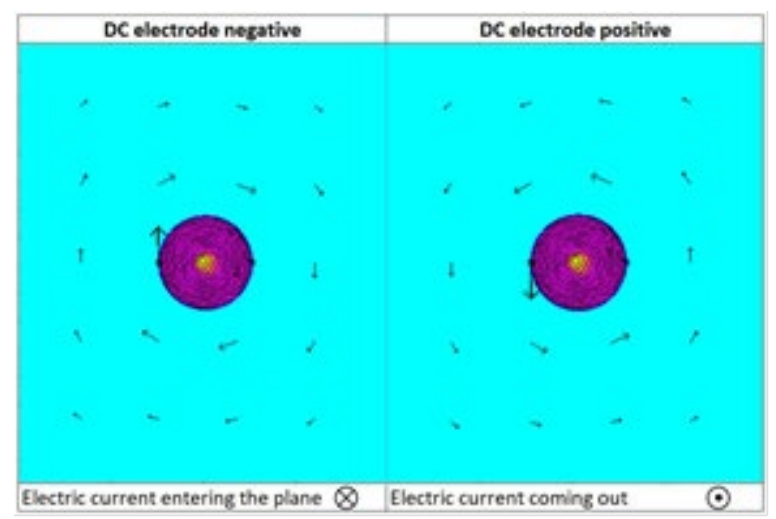

Figure 2. Electromagnetic field generated by the electric arc.

There is an interaction between the electromagnetic field generated by the straight wire and the electromagnetic field generated by helical coils arranged in the metal air gap. The analysis of the resulting forces (Lorentz force) was carried out from this interaction of the electromagnetic field generated by the coil, with the electric arc charge. The field lines are perpendicular to the direction of the negative charges of the electric arc, resulting in a force orthogonal to the plane formed by the charge vector and the field vector.

Using a three-dimensional Cartesian system, as shown in Figure 3, it is possible to identify the relative directions of the magnetic force $(F)$, speed $(v)$ and magnetic field $(B)$ when acting on a charge $(q)$. They are related by means of a vector product, in which the force is orthogonal to the plane formed by the magnetic field and the speed of the charge [21,24]. 


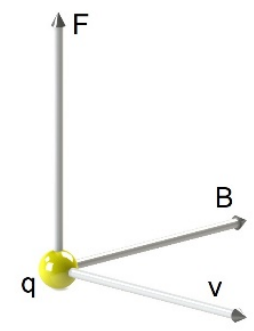

Figure 3. Three-dimensional Cartesian system (F; B; v).

When observing a section of the central area shown in Figure 4, the area around the electric arc stands out; the resulting forces are perpendicular to any point considered on the electromagnetic field lines. In this way, there is a distribution of forces around the area of the electric arc, changing the shape of the electric arc from circular (dashed line) to elliptical (continuous line). Towards the center of the arc there are compression forces, while in the opposite direction there are traction forces.

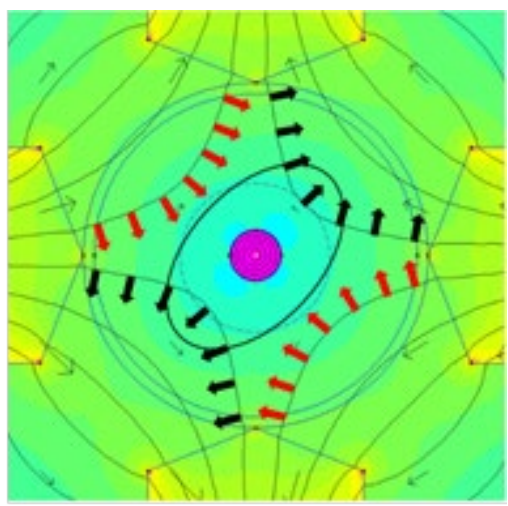

Figure 4. Distribution of forces around the electric arc.

The resulting compression forces are applied in orthogonal planes to the traction forces. Figure 5 indicates the resultant of the forces around the electric arc in the different combinations of polarity and connection of the coils, and the expected elliptical profile of the weld pool.

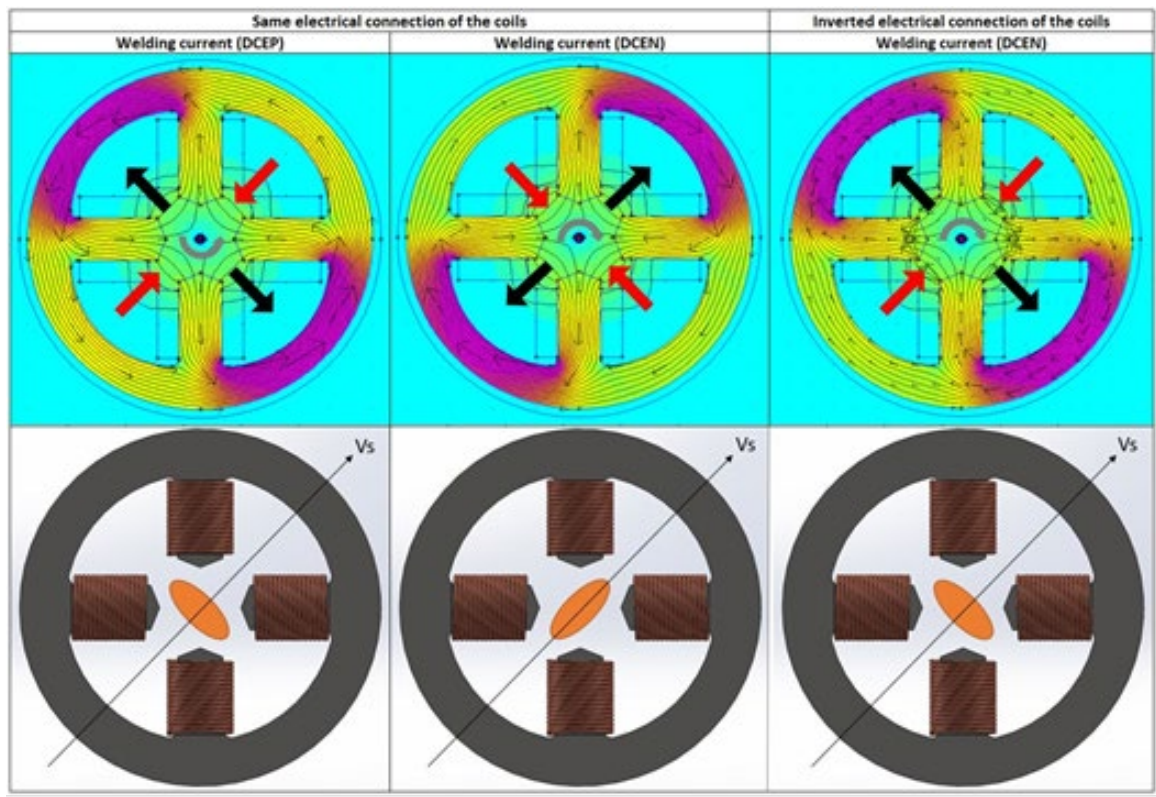

Figure 5. Distribution of traction and compression forces on the electric arc. 
The diagonal arrow indicates the welding direction and represents the displacement direction at a welding speed (Vs). Based on the simulations, it is possible to change the shape of the electric arc profile, providing an elliptical pool directed in the direction of welding or perpendicular to that of welding.

The density of the magnetic flux was obtained from the interaction of the magnetic field in the electrode, generated by the welding current with the magnetic field of the constricting device, generated by the current in the coils. In Figure 6 , the flow position in relation to the tungsten electrode and the ceramic nozzle is highlighted.

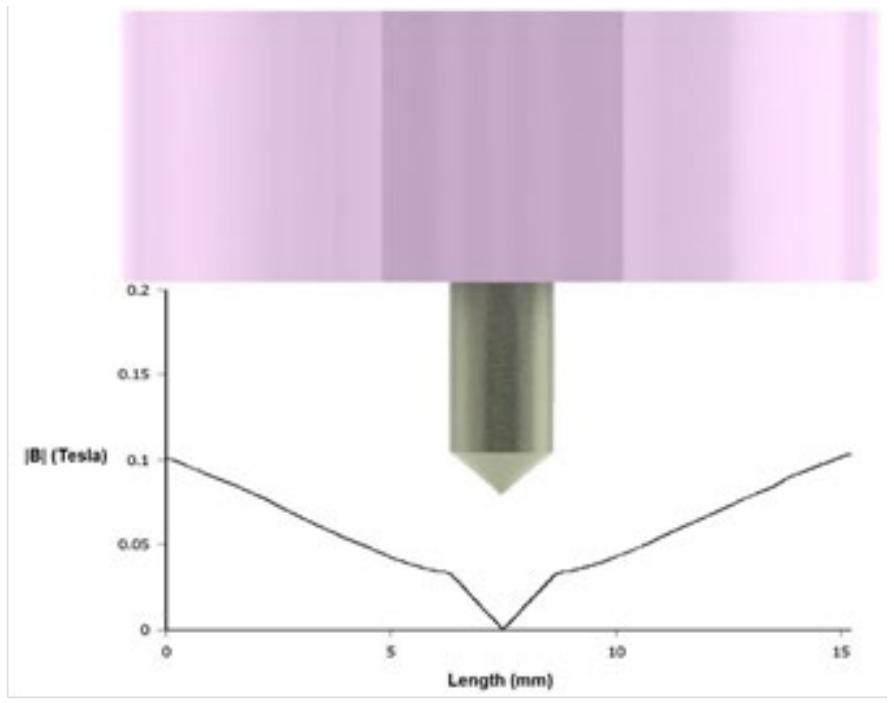

Figure 6. Density of magnetic flux in the arc region.

The flow tends to zero in the center of the electrode and increases as it approaches the edges of the ceramic nozzle. The resulting forces are maximum at the arc edge and decrease towards the center of the arc. In the central area of the electric arc, the resulting forces are zero.

\subsection{Three-dimensional Modeling and Construction of the Constrictor Device}

After the electromagnetic simulation, the three-dimensional modeling, adequacy of the constrictor device dimensions and the manufacturing process alternatives for each component began. The air gap configuration that showed the best performance in electromagnetic simulations was the cylindrical one with the four equidistant rods. Figure 7 shows the 3D modeling and the constrictor device already manufactured.

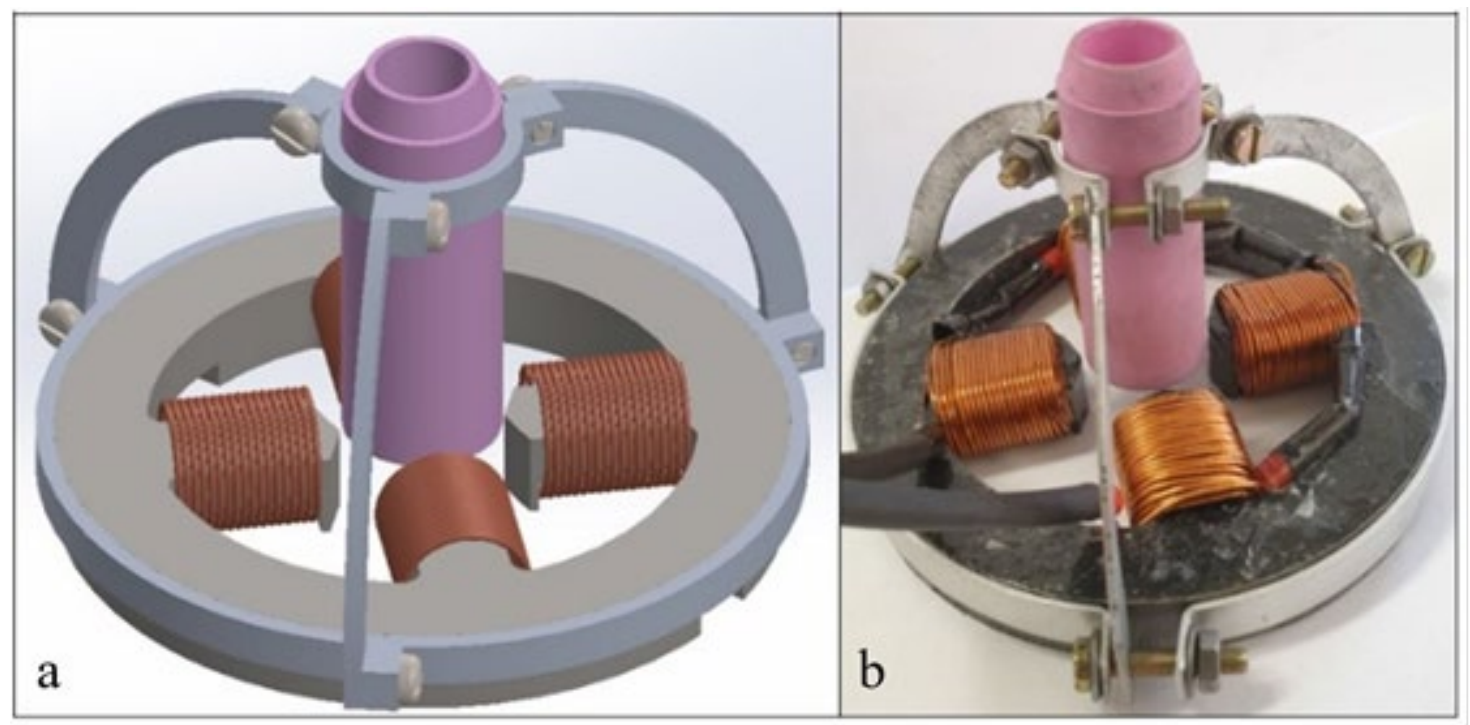

Figure 7. 3D Modeling (a) and manufactured constrictor device (b). 
The concept for the constricting device is that it should function as an accessory, enabling assembly and disassembly without changing the characteristics of the welding torch. This accessory allows it to be mounted on the ceramic nozzle of the GTAW process and the electrical connection of the coils has only two terminals, one positive and the other negative, thus simplifying the electrical connection process. In order to manufacture the support for the helical coils, which are positioned transversal to the electric arc, an air gap was designed to hold the coil set.

\subsection{Experiment setup}

The heat source used to open the electric arc, initially arc on plate metal and later bead on plate metal, was a MaxxiTIG 200P AC/DC multi-process inverter source, which provides a welding current range of 5 to $200 \mathrm{~A}$ in direct current, when operating in the GTAW process.

The inert gas used was industrial argon ( $\mathrm{Ar}$ ) with $99.99 \%$ purity and a flow rate of $11 \mathrm{~L} / \mathrm{min}$. A non-consumable electrode (AWS EWTh-2) made of tungsten and doped with thorium (2\%) of $2.4 \mathrm{~mm}$ in diameter and sharpening angle of $70^{\circ}$ was used. The base metal used was $10 \mathrm{~mm}$ SAE 1020 carbon steel. The welding parameters used were as described in Table 1 and the assembly on the device was carried out according to Figure 8.

Table 1. Welding parameters on sheet metal.

\begin{tabular}{cc}
\hline Welding parameters & Values \\
Welding speed & $2.5 \mathrm{~mm} / \mathrm{s}$ \\
Argon flow & $11 \mathrm{~L} / \mathrm{min}$ \\
Ceramic nozzle N 8 (internal diameter) & $12.7 \mathrm{~mm}$ \\
EWTh (Tungsten electrode: 2\% thorium) & $2.4 \mathrm{~mm}$ \\
Sharpening angle & $70^{\circ}$ \\
Welding polarity & DCEN \\
Welding current & $120 \mathrm{~A}$ \\
Coil current & $5 \mathrm{~A}$ \\
Electrode-workpiece distance (la) & $5 \mathrm{~mm}$ \\
Contact Tip-Workpiece Distance & $10 \mathrm{~mm}$ \\
Plate thickness & $10 \mathrm{~mm}$ \\
Welding position & Flat position \\
\hline
\end{tabular}

The constricting device operated with a current of 5 A powered by an Instrutherm DC Power Supply FA-3050 direct current source. The distance from the ceramic nozzle to the base piece (BP) was $10 \mathrm{~mm}$, while the length of the arc (la) was kept at $5 \mathrm{~mm}$ with the aid of a template.

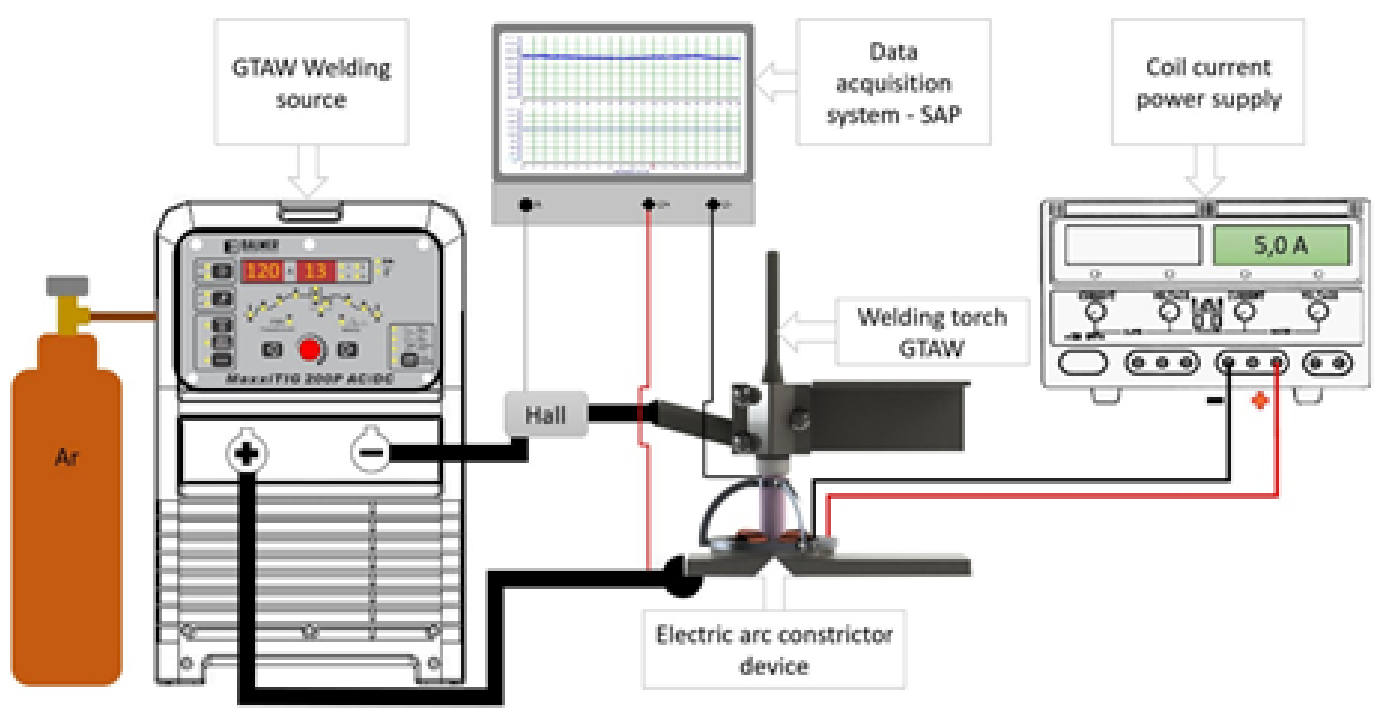

Figure 8. Mounting the constrictor device on the workbench. 
The constricting device was positioned concentrically to the tungsten electrode, with its upper part aligned with the edge of the ceramic nozzle. The directing rods of the electromagnetic field enable the electric arc to be immersed in this generated field. The fixation of the constricting device was made directly on the ceramic nozzle, acting as an accessory that can be assembled and disassembled without changing the original characteristics of the torch. In addition to the constricting device, the torch fixation is also shown.

For the metallographic analysis of the beads on plate, the specimens were sectioned transversely to the welding direction, in the middle of the weld bead. The specimens obtained were embedded in bakelite and the sequentially 100, 220, 320, 400, 600,1200 and 2500 mesh sandpaper were used. The preparation with the sandpaper was manual under running water and later polished with alumina (aluminum oxide) in suspension with an average particle size of $1 \mu \mathrm{m}$. For polishing, a $200 \mathrm{~mm}$ diameter metallographic cloth was used, fixed on the polishing plate at a rotation of $150 \mathrm{rpm}$. The abrasive processes were followed by a etching with Nital $5 \%\left(5 \% \mathrm{HNO}_{3}+95 \%\right.$ ethyl alcohol).

Image acquisition was performed with an Olympus Bx60M microscope with a coupled camera model ToupCam UCMOS3100KPA with the TP603100A lens with a resolution of $3.1 \mathrm{MP}$.

The footage of the electric arc during the transition from the arc without constriction to the arc with electromagnetic constriction was performed with a high-speed Phantom Miro LAB110 camera with an acquisition rate of $1000 \mathrm{fps}$ and a No. 8 welding lens positioned in front of the camera. The software of the camera Phantom Video Player and PCC 3.4 was used, in which the transition time for constriction of the electric arc and the dimension of this constriction were analyzed.

\section{Results}

\subsection{Arc on plate}

The constricting device performed the simultaneous and perpendicular effect of the compression and traction forces on the arc, which granted the elliptical shape of the electric arc. This geometric arrangement inserts an orientation in the transverse profile of the electric arc and, consequently, in the melting pool, which enables to direct the electric arc.

Three different conditions were tested, initially the opening of the electric arc over the plate without effect of the electromagnetic field shown in Figure 9a, called a circular arc. Subsequently, with the activation of the electromagnetic field, inserting the elliptical shape of the electric arc in the transverse direction to the welding, as indicated in Figure $9 \mathrm{~b}$, called the transverse elliptical arc.

In the configuration shown in Figure 9c, called the longitudinal elliptical arc, the elliptical profile of the electric arc is directed in the longitudinal direction to that of the welding. To change the orientation from $b$ to $c$, there is only the reversion of the electrical connection of the coil, eliminating any mechanical movement.

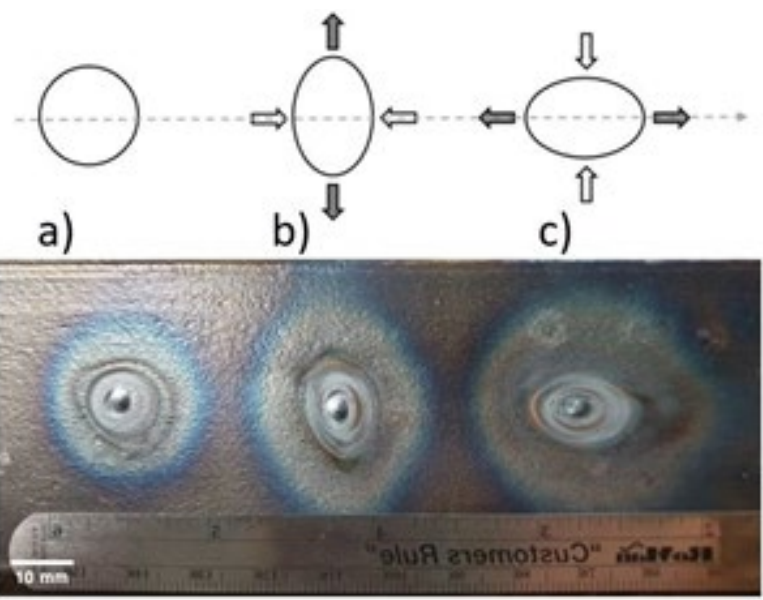

Figure 9. Impressions of the electric arc on sheet.

The opening of the electric arc on plate with the effect of the electromagnetic field generated by the coils, changed the electric arc from circular to elliptical. It was verified, in a qualitative way, the modification of the weld pool geometry.

\subsection{Recording the Arc Profile}

The alteration of the side profile of the electric arc, with and without constriction, can be seen in Figure 10. When using the proprietary software of the camera, an analysis of the transition time and the dimension of this constriction was made, 
between the arc without constriction and the arch with constriction. In addition, the time to complete the shape transition of the side profile of the electric arc was measured. The time for constriction is of 8 milliseconds (ms).

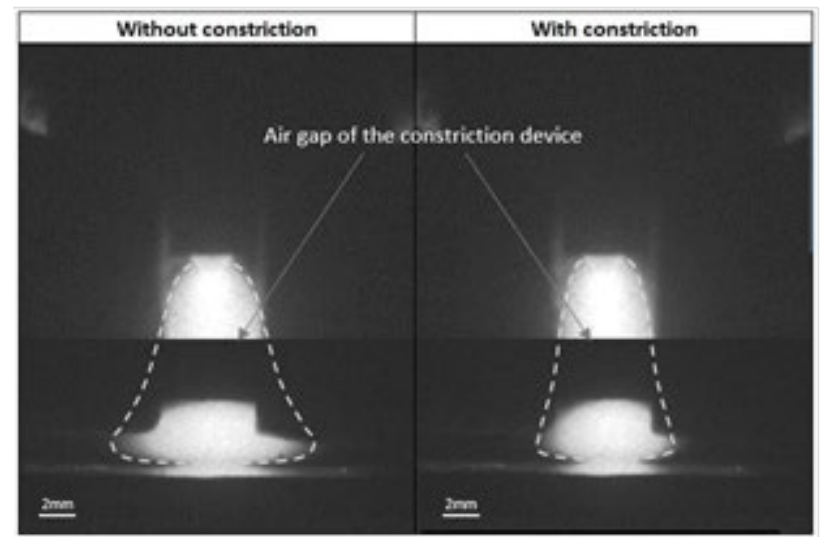

Figure 10. Footage of the electric arc's constriction.

Addressing the dimensional issue, measured in the area of contact between the electric arc and the base metal, the right lateral constriction and the left lateral constriction were $2,0 \pm 0,2 \mathrm{~mm}$. The measurements of the dimension of the lateral constriction confirm that there is a change in the lateral profile of the electric arc due to electromagnetic constriction.

\subsection{Constriction of the Electric Arc applied to the bead on plate}

In this step, the influence of the constriction of the electric arc in the shape alteration of the weld pool and the changes in geometric characteristics of the bead on plate was quantitatively investigated.

Three welding conditions were performed: arc without constriction, arc with constriction orienting the ellipse longitudinally to the welding direction, and finally the arc with constriction orienting the ellipse transversely to the welding direction.

A total of 3 specimens were produced. The electrical welding parameters, as well as the geometric positioning, were identical for the three conditions. The only variable was the electromagnetic constriction of the arc, with means to verify the influence of this parameter on the process. The welding parameters were defined in preliminary tests and based on the visual aspect of the deposited beads.

It is observed in Figure 11, from left to right, the circular arc shape that represents the non-activation of the coils, while the longitudinal elliptical arc shape and the transversal elliptical arc shape that represent the activation of the coils. The welding direction is considered leaving the page. On the macrographs, there is the representation of the ceramic nozzle, the electric arc and the base piece, as well as the arrows that represent the acting forces.

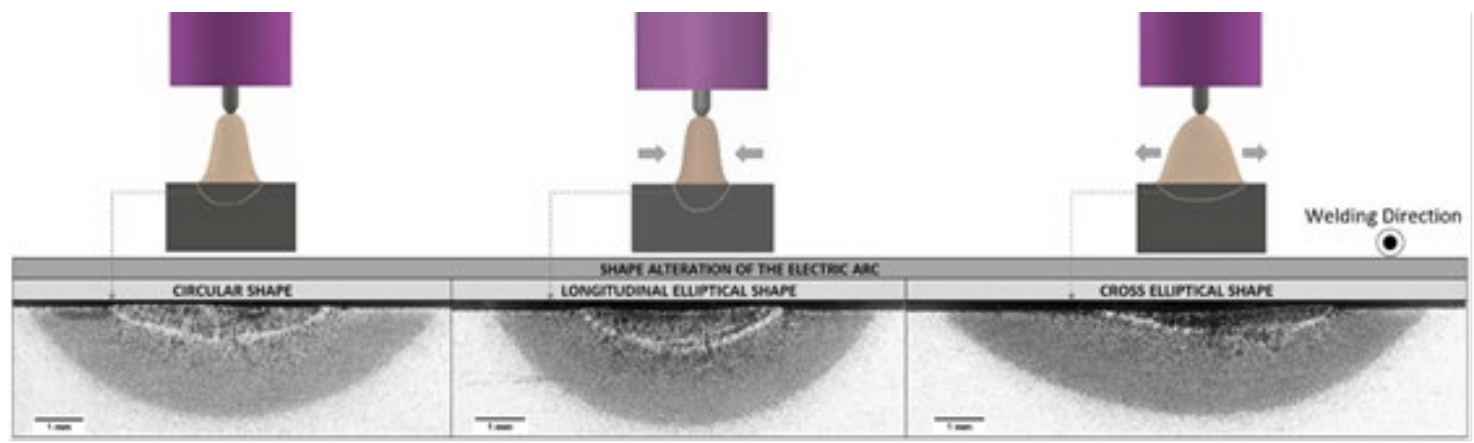

Figure 11. Metallography of the beads on plate and arc shape.

It should be noted that in the two situations where the coil was activated, there was no mechanical movement of the constrictor device, but the inversion of the electrical supply of the coils.

The measurements of the penetration and width dimensions were performed using the ImageJ software and are shown in Figure 12 with their respective standard deviations. From left to right, the data are presented in the same sequence as in Figure 11. Three measurements were taken for each condition. 


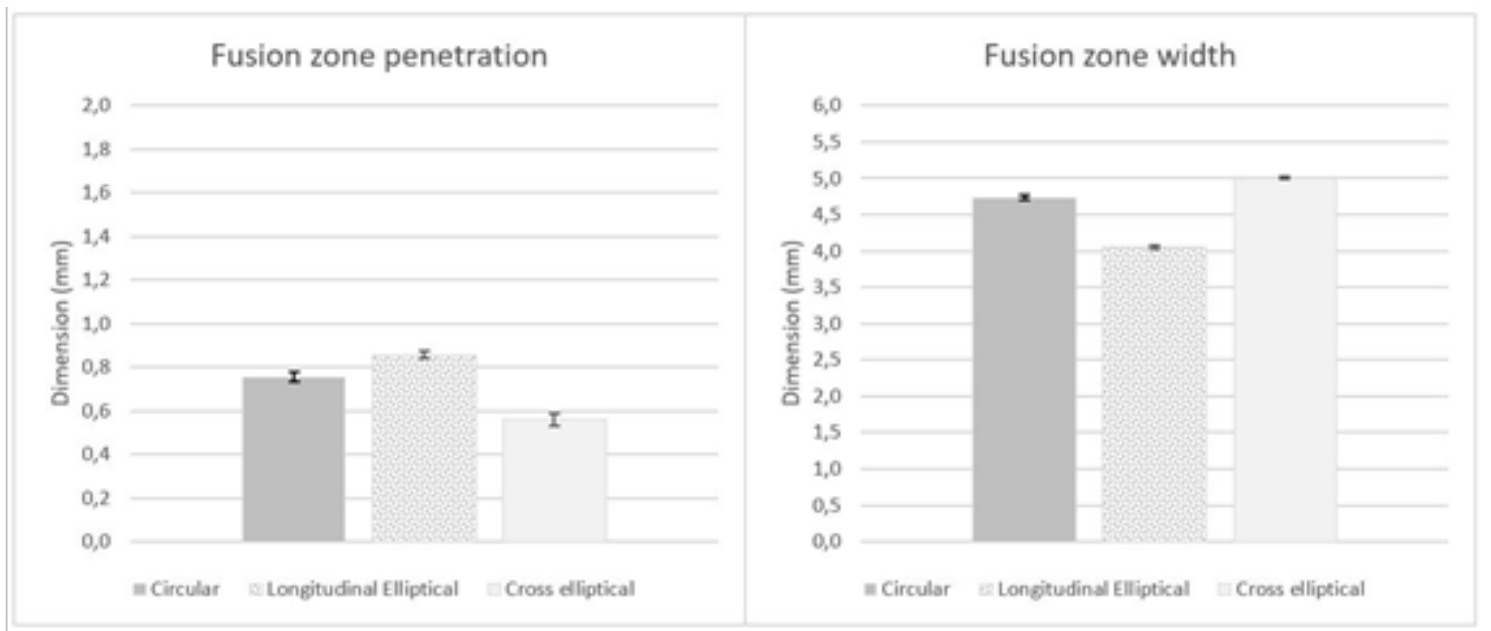

Figure 12. Penetration and width of fusion zone.

Compared to the effect of the circular electric arc with no electromagnetic constriction, there was an increase in penetration when using the longitudinal elliptical arc and a decrease when using the transverse elliptical arc. The width, on the other hand, had the opposite effect, decreasing when applying the longitudinal elliptical arc and increasing when using the transverse elliptical arc. The greatest penetration and the smallest width were obtained with the longitudinal elliptical arc. As the constriction modifies the cross section of the electric arc and the contact region of the electric arc with the workpiece, the same behavior for the change in width and penetration is observed in the heat affected zone.

The penetration and width measurements confirm the change in the shape of the weld pool due to the arc's electromagnetic constriction, which are reflected to the geometric characteristics of the bead deposited by the modified electric arc.

Current and voltage oscillograms were obtained using the portable acquisition system (SAP) V4.37. An interval of 20 seconds was analyzed and it contains 100,000 points for each channel analyzed, with acquisition rate of $5 \mathrm{kHz}$. Based on these points, the average and standard deviation of the welding current and voltage were calculated, both for the condition without and with electromagnetic constriction of the arc. Figure 13 shows the average values of current and voltage with their respective standard deviations.

As the welding source has a constant current characteristic, the average welding current remained close to $122.2 \mathrm{~A}$. The voltage, shown in the crosshatched bars, dropped by $0.54 \mathrm{~V}$ under the effect of the constricting device and with standard deviation of approximately $0.3 \mathrm{~V}$.

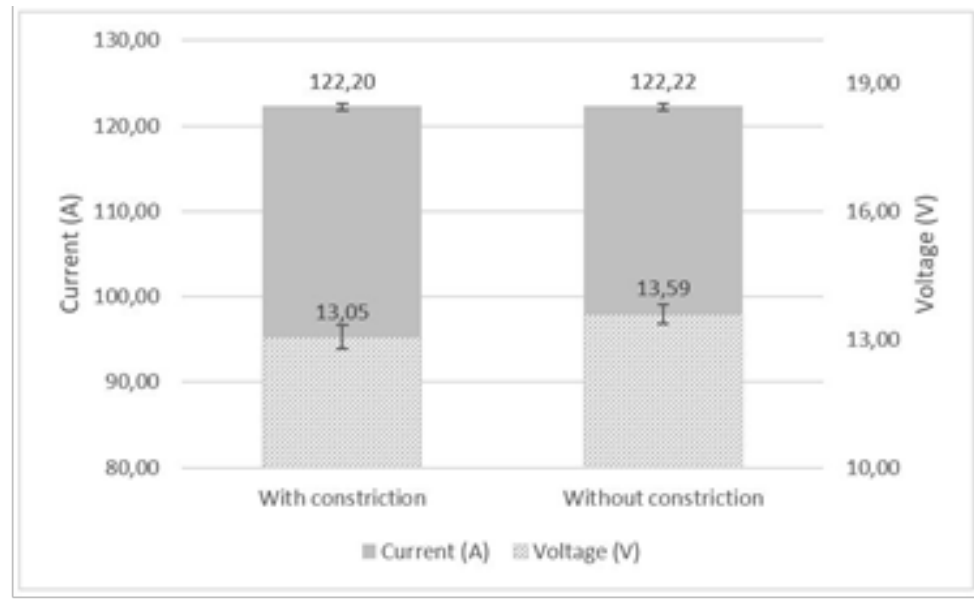

Figure 13. Effect of arc constriction on welding current and arc voltage.

Based on the width results of the fused area, the weld pool area values were obtained. For the elliptical weld pool, the union of the longitudinal and transversal condition was estimated. Figure 14 shows the areas for the circular and elliptical arcs. The values were obtained with a precision of two decimal points based on the data acquisition system. 
Inserting the values obtained for current, voltage and area, in Equation 1, the specific power was calculated. As the only parameter changed was the activation of the coils, the same value was maintained for the thermal efficiency $(\eta=0.75)$ using the GTAW process (DCEN) [25].

\begin{tabular}{|l|c|l|l|l|}
\hline \multicolumn{2}{|c|}{ Circular shape } & \multicolumn{3}{|c|}{ Elliptical shape } \\
\hline & & & & \\
\hline
\end{tabular}

Figure 14. Weld pool area and specific power.

The area of the weld pool is reduced with the constriction of the arc. When changing the contact area of the electric arc with the part $\left(A_{0}\right)$, the specific power changes. Keeping the other factors equal, the decrease in area led to an increase in specific power.

For the two conditions of electromagnetic constriction of the arc, the longitudinal elliptical arc and the transversal elliptical arc, the same specific power was considered. The justification for the same specific power to have different penetrations is based on Figure 15.

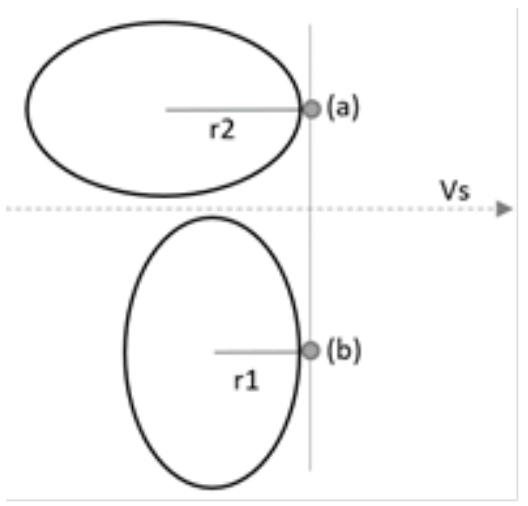

Figure 15. Arc time over a point

The only altered parameter was the orientation of the arc constriction, which changes the direction of the ellipse, so that the point (a) remained under the electric arc for 2.0 seconds, which increased the penetration of the longitudinal elliptical arc. The point (b), on the other hand, remained for 1.6 seconds and the decrease in contact time with the fused area results in less penetration for the cross elliptical arc.

\section{Conclusion}

This work presented the use of an electric arc constrictor device capable of altering the geometric characteristics of the weld bead. According to the results presented, it is possible to conclude:

(1) The electromagnetic constrictor device of the electric arc provides the change in the shape of the electric arc from circular to elliptical, and this change allows directing the arc in the longitudinal and transverse to the welding direction;

(2) The electromagnetic constriction device of the electric arc can be used as an accessory, regardless of the GTAW equipment used. It is independent of the equipment;

(3) The constriction of the electric arc causes an increase in specific power; 
(4) Changing the orientation of the ellipse results in different penetration and width when applying the electromagnetic constriction of the arc in beads on plate. With the greater length of the ellipse directed in the welding direction, it has the greatest penetration and the smallest bead width;

(5) Different penetrations are obtained, for the same specific power, due to the different exposure times of the base metal to the modified electric arc area.

(6) The constricting device can be used in metallic coating processes when the coils are adjusted to produce a wider weld bead and less penetration. With this device it is possible to decrease the dilution rate of the weld beads suggesting the application in coating operations.

\section{Acknowledgments}

Thanks to the Technical College of Santa Maria, at the Federal University of Santa Maria, for believing in the qualification of its teaching staff. Also, the Federal University of Minas Gerais for welcoming the author.

\section{References}

[1] Chigarev VV, Shchetinina VI, Shthetinin SV. Magnetic field in electric arc welding. Welding International. 2016;30(4):319-324. http://dx.doi.org/10.1080/01431161.2015.1058008.

[2] Baskoro AS, Frisman S, Yogi A, Winarto W. Improvement of Tungsten Inert Gas (TIG) welding penetration using the effect of electromagnetic field. Applied Mechanics and Materials. 2014;493:558-563.

[3] Luo J, Luo Q, Wang X, Wang X. EMS-CO2 welding: a new approach to improve droplet transfer characteristics and welding formation. Materials and Manufacturing Processes. 2010;25(11):1233-1241. http://dx.doi.org/10.1080/10426914.2010.481000.

[4] Reis RP, Scotti A, Norrish J, Cuiuri D. Investigation on welding arc interruptions in the presence of magnetic fields: arc length, torch angle and current pulsing frequency influence. IEEE Transactions on Plasma Science. 2012;41(1):133-139. http://dx.doi.org/10.1109/TPS.2012.2230650.

[5] Shoichi M, Yukio M, Koki T, Yasushi T, Yukinori M, Yusuke M. Study on the application for electromagnetic controlled molten pool welding process in overhead and flat position welding. Science and Technology of Welding and Joining. 2013;18(1):38-44. http://dx.doi.org/10.1179/1362171812Y.0000000070.

[6] Lee S, Kim J, Lee BY, Lee SY. The effect of external electromagnetic force in gas metal arc welding on the transfer mode. Key Engineering Materials, 2005;297-300:2825-2830.

[7] Li Y, Wu C, Wang L, Gao J. Analysis of additional electromagnetic force for mitigating the humping bead in high-speed gas metal arc welding. Journal of Materials Processing Technology. 2016;229:207-215. http://dx.doi.org/10.1016/j.jmatprotec.2015.09.014.

[8] Greene WJ. Magnetic oscillation of welding arc. United States patent US US2920183A. 1957 Feb. 12

[9] Wu H, Chang Y, Lu L, Bai J. Review on magnetically controlled arc welding process. International Journal of Advanced Manufacturing Technology. 2017;91(9-12):4263-4273. http://dx.doi.org/10.1007/s00170-017-0068-9.

[10] Corradi DR, Bracarense AQ, Wu B, Cuiuri D, Pan Z, Li H. Effect of Magnetic Arc Oscillation on the geometry of single-pass multi-layer walls and the process stability in wire and arc additive manufacturing. Journal of Materials Processing Technology. 2020;283:116723. http://dx.doi.org/10.1016/j.jmatprotec.2020.116723.

[11] Yunlong C, Mingxu L, Lin L, Babkin A, Lee B-Y. The influence of longitudinal magnetic field on the CO2 arc shape. Plasma Science \& Technology. 2015;17(4):321-326. http://dx.doi.org/10.1088/1009-0630/17/4/11.

[12] Sun Q, Li J, Liu Y, Jiang Y, Kang K, Feng J. Arc characteristics and droplet transfer process in CMT welding with a magnetic field. Journal of Manufacturing Processes. 2018;32:48-56. http://dx.doi.org/10.1016/j.jmapro.2018.01.017.

[13] Liu Y, Li J, Sun Q, Jin P, Sun Q, Li B, et al. Optimization of magnetic oscillation system and microstructural characteristics in arc welding of Al/Mg alloys. Journal of Manufacturing Processes. 2019;39:69-78. http://dx.doi.org/10.1016/j.jmapro.2019.02.008.

[14] Liu Y, Sun Q, Liu J, Wang S, Feng J. Effect of axial external magnetic field on cold metal transfer welds of aluminum alloy and stainless steel. Materials Letters. 2015;152:29-31. http://dx.doi.org/10.1016/j.matlet.2015.03.077.

[15] Nomura K, Morisaki K, Hirata Y. Magnetic control of arc plasma and its modelling. Welding in the World. 2009;53(7-8):R181-R187. http://dx.doi.org/10.1007/BF03266730.

[16] Nomura K, Ogino Y, Haga T, Hirata Y. Influence of magnet configurations on magnetic controlled TIG arc welding. Transactions of JWRI. 2010;39:209-210.

[17] Nomura K, Ogino Y, Hirata Y. Shape control of TIG arc plasma by cusp-type magnetic field with permanent magnet. Welding International. 2012;26(10):759-764. http://dx.doi.org/10.1080/09507116.2011.592691. 
[18] Liu S, Liu ZM, Zhao XC, Fan XG. Influence of cusp magnetic field configuration on K-TIG welding arc penetration behavior. Journal of Manufacturing Processes. 2020;53:229-237. http://dx.doi.org/10.1016/j.jmapro.2020.02.027.

[19] Modenesi PJ. Introdução à Física do Arco Elétrico Soldagem I. Belo Horizonte: UFMG; 2001.

[20] Marques PV, Modenesi PJ. Some handy equations for welding. Soldagem e Inspeção. 2014;19:91-101. http://dx.doi.org/10.1590/S010492242014000100011.

[21] Resnick R, Walker J, Halliday D. Fundamentals of physics. Hoboken: John Wiley; 1988.

[22] Graça C. Eletromagnetismo. Rio Grande do Sul: Universidade Federal de Santa Maria; 2012.

[23] Lancaster JF. The physics of welding. Physics in Technology. 1984;15(2):73. http://dx.doi.org/10.1088/0305-4624/15/2/105.

[24] Crowell B. Electricity and magnetism: Light and Matter. Fullerton, CA: Benjamin Crowell; 2000.

[25] Kou S. Welding metallurgy, 2nd ed. New Jersey: John Wiley \& Sons, Inc.; 2003 